\title{
Fundamental melting process of water-insoluble phase change material immersed in water
}

\author{
Tsuyoshi KAWANAMI*, Ryota HIRAI**, Katsuaki SHIRAI*** and Shigeki HIRASAWA** \\ * Department of Mechanical Engineering Informatics, Meiji University \\ 1-1-1 Higashi-Mita, Tama-ku, Kawasaki 214-8571, Japan \\ E-mail: kawanami@meiji.ac.jp \\ ** Department of Mechanical Engineering, Kobe University \\ 1-1 Rokkodai-cho, Nada-ku, Kobe 657-8501, Japan \\ *** Department of Mechanical Engineering, Shibaura Institute of Technology \\ 3-7-5 Toyosu, Koto-ku, Tokyo 135-8548, Japan
}

Received: 13 July 2017; Revised: 30 September 2017; Accepted: 22 November 2017

\begin{abstract}
This study examined the melting behavior and heat transfer characteristics of a water-insoluble material immersed in water. $\mathrm{n}$-Hexadecane, popularly used as a phase change material, was selected as the water-insoluble material. A rectangular $n$-hexadecane solid was immersed in water. The $n$-hexadecane block was then vertically fixed onto the copper plate of the cooling wall. The flow structure of the free convection of water was visualized by mixing tracer particles with the water, and a laser sheet entered from the opposite side of the cooling wall as a light source. Its melting behavior and melting rate were then observed under various water temperatures in a test vessel. The local heat transfer coefficients of $n$-hexadecane were calculated from its melting rate and latent heat. In addition, the thickness of the melting liquid of $n$-hexadecane was calculated using a simple analysis model. As the experimental results, it flows upward along the n-hexadecane block, accumulates at the top of the solid as a droplet, and then flows upward vertically because the melting liquid of n-hexadecane does not diffuse in water. The calculated thickness of the melting liquid of n-hexadecane increases drastically near the lower end and increases almost monotonically and at a mild rate in other parts of the block. The analytical and experimental local heat transfer coefficients showed good agreement at low water temperatures. The calculated local heat transfer coefficients changed slightly, except for those at the top and low parts of the block. The local heat transfer coefficients increased in most locations as time elapsed in the experiment.
\end{abstract}

Keywords : Latent heat, Phase change material, Thermal energy storage, Heat transfer, Natural convection

\section{Introduction}

The utilization of waste heat is one of the potential solutions to global warming. However, it is rarely adopted because waste heat cannot be used without thermal energy storage (TES) technologies, which are available for long distance transport or long-term storage. Latent heat storage (LHS) is an example of a TES technology, which can store large amounts of thermal energy using the latent heat of a phase change material (PCM) (Yamada et al., 2006, Nomura et al., 2010, Veerakumar et al., 2016, Bosholm et al., 2016). In general, the latent heat of solidification and melting are used in LHS devices. Therefore, it is important to investigate the melting behavior of PCMs in order to design an LHS device. For example, the melting of a PCM in an inclined rectangular cross section was investigated by Saito et al. (1989). The study found that that their numerical method accurately analyzed melting behavior and showed detailed results on the contacting mode variations in an inclined heat transfer surface, the relation between the mean heat flux and inclination angle, heat flux variations on respective walls, pressure and shear stress distributions in the liquid layer, and heat transfer characteristics. A PCM is often encased in the heat exchanger of LHS devices in order to prevent leakage of the PCM in liquid phase. One problem with LHS devices is thermal resistance, which occurs when the heat transfer of the wall of the 
PCM case is lower than the other parts of the device. In some studies, fins were installed in the heat exchanger to expand the heating surface area, but the net thermal energy storage rate was compromised. Direct heat exchange, which involves liquids that are insoluble in each other, can eliminate the thermal resistance of the wall and separate the PCM liquid and heat transfer fluid in an LHS device. The melting behavior of liquids that are insoluble in each other is expected to be different from the melting behavior of liquids that are soluble in each other. Experiments on the melting of ice in immiscible liquids have been reported by Yamada et al. (1997). The study found that the local heat transfer coefficient was a strong function of the distance from the top of the ice block as well as the ambient liquid temperature. The direct contact heat storage and release characteristics of erythritol as a PCM with oil have also been investigated in a vessel with a partition plate (Horibe et al., 2015). The study reported that melting time decreased with increasing oil flow rate, and was accelerated by the effect of the heat conductivity of the perforated partition plate. In these studies, the melting liquid of a PCM flowed downward owing to the density difference between the PCM and ambient liquid. On the other hand, the melting liquid flowed upward owing to direct heat exchange when paraffin was used as the PCM and water as the heat exchange fluid. The melting characteristics of water-insoluble materials in water have not been systematically investigated. Especially, the effect of molten liquid from water-insoluble materials to the heat transport mechanism remain unclear. The remarkable pointe of this research is to enhance the heat transport by controlling the flow of melting liquid of water-insoluble PCM. The aim of this study is to investigate the fundamental melting behavior and the melting heat transfer characteristics between the water-insoluble materials and the ambient water contact with the melting liquid through experimental and numerical studies.

\section{Nomenclature}

$\begin{array}{ll}a & \text { thermal diffusivity }\left(\mathrm{m}^{2} \mathrm{~s}^{-1}\right) \\ b & \text { thickness of n-hexadecane }(\mathrm{m}) \\ c & \text { specific heat capacity }\left(\mathrm{J} \mathrm{kg}^{-1} \mathrm{~K}^{-1}\right) \\ g & \text { gravitational acceleration }\left(\mathrm{m} \mathrm{s}^{-2}\right) \\ G r & \text { Grashof number } \\ h & \text { local heat transfer coefficient }\left(\mathrm{W} \mathrm{m}^{-2} \mathrm{~K}^{-1}\right) \\ L & \text { latent heat }\left(\mathrm{J} \mathrm{kg}^{-1}\right) \\ l & \text { length }(\mathrm{m}) \\ N u & \text { Nusselt number } \\ P r & \text { Prandtl number } \\ Q & \text { heat transfer rate }(\mathrm{W}) \\ R e & \text { Reynolds number } \\ S t e & \text { Stefan number } \\ T & \text { temperature }\left({ }^{\circ} \mathrm{C}\right) \\ t & \text { elapsed time (s) } \\ u & \text { velocity of } x \text {-direction }\left(\mathrm{m} \mathrm{s}^{-1}\right) \\ w & \text { velocity of } y \text {-direction }\left(\mathrm{m} \mathrm{s}^{-1}\right) \\ x & \text { distance from the lower end of the n-hexadecane block (m) } \\ y & \text { distance from the surface of the } \mathrm{n} \text {-hexadecane block (m) }\end{array}$

\section{Greek}

kinematic viscosity $\left(\mathrm{m}^{2} \mathrm{~s}^{-1}\right)$ 


$$
\begin{array}{ll}
\rho & \text { density }\left(\mathrm{kg} \mathrm{m}^{-3}\right) \\
\mu & \text { viscosity }(\mathrm{Pa} \mathrm{s})
\end{array}
$$

$\begin{array}{ll}\text { Subscript } & \\ 0 & \text { initial state } \\ \infty & \text { water in vessel } \\ \text { ave } & \text { average } \\ \mathrm{cw} & \text { cooling wall } \\ 1 & \text { liquid } \\ \mathrm{m} & \text { melting liquid } \\ \mathrm{mp} & \text { melting point } \\ \mathrm{S} & \text { solid } \\ \mathrm{w} & \text { water }\end{array}$

\section{Experimental apparatus and procedures}

\subsection{Experimental apparatus experimental procedures}

A schematic of the experimental apparatus is shown in Figure 1. The basic components of the apparatus are the test vessel, cooling wall, cooling water circulating systems, laser systems, and associated instrumentation.

The dimensions of the test vessel made of PMMA (Polymethyl methacrylate) was $390 \mathrm{~mm} \times 195 \mathrm{~mm} \times 290 \mathrm{~mm}$, and it was covered with thermal insulation that was $50 \mathrm{~mm}$ thick. The insulation at the laser incidence and the sides were removable so that photographs could be taken. The water level from the bottom of the test vessel was set to $150 \mathrm{~mm}$. The cooling wall consisted of a copper plate with $3 \mathrm{~mm}$ thick; an acrylic vessel measuring $150 \mathrm{~mm}$ in width, $100 \mathrm{~mm}$ in height, and $30 \mathrm{~mm}$ in depth; and circulating systems of the cooling water. Temperature-regulated water from a thermostatic bath was circulated through the cooling vessel to maintain the temperature of the copper plate surface at preselected temperatures. The temperature of the ambient water was measured using three copper-constantan thermocouples. The installed position of thermocouples is at $10 \mathrm{~mm}, 75 \mathrm{~mm}$, and $140 \mathrm{~mm}$ from the bottom of the test vessel for the vertical direction and at $65 \mathrm{~mm}$ from the side end of the cooling vessel in the depth direction along the cooling wall surface for the horizontal position. The mean temperature of these measurements was defined as the temperature of ambient water $T_{\infty}$ as the initial temperature set $T_{0}$. The difference of each value was confirmed within $\pm 0.2 \mathrm{~K}$ at a maximum.

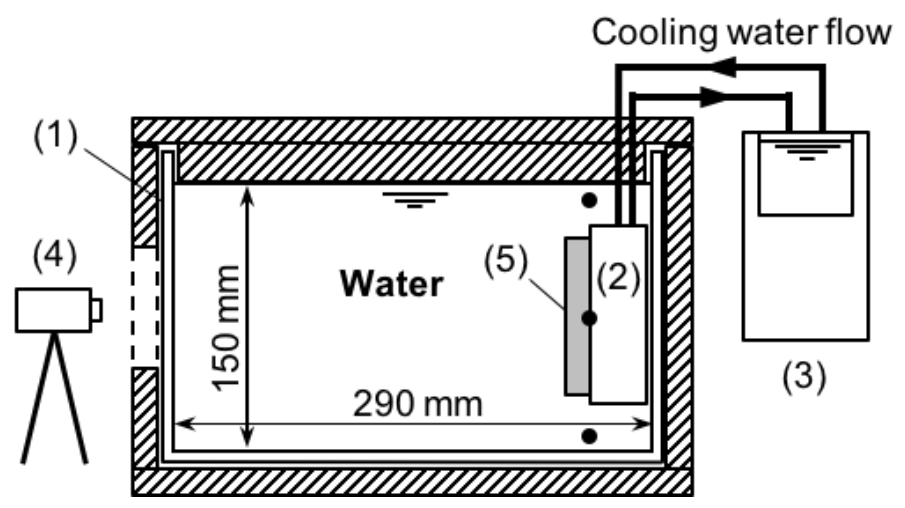
(1) Test vessel
(2) Cooling wall
(3) Thermostatic bath
(4) Laser
(5) Hexadecane block
- Thermocouples
$\mathbb{Z}$ Thermal insulation

Figure 1. Schematic of the experimental apparatus 


\subsection{Experimental procedures}

n-Hexadecane was selected as the water-insoluble material. First of all, solid n-hexadecane was placed in a heatresistant beaker and heated to $190^{\circ} \mathrm{C}$ using a mantle heater. It was kept for 10 minutes for degassing. Then remove a beaker from a mantle heater and pour a small amount into an acrylic vessel with internal dimensions of $150 \mathrm{~mm}$ in width, $100 \mathrm{~mm}$ in height, and $25 \mathrm{~mm}$ in depth. After that, the container wad cooled in a temperature-set incubator. This operation was repeated, and a rectangular solid flat plate sample having a width of $150 \mathrm{~mm}$, a height of $100 \mathrm{~mm}$, and a depth of 25 mm was molded. The appearance of the testing $n$-hexadecane is shown in Figure 2. The temperature of the water in the test vessel was maintained at the preselected temperature. The n-hexadecane block was then vertically fixed onto the copper plate of the cooling wall. The shape of the melting n-hexadecane block and the flow image of the melting liquid were recorded from the front side through the observation window at preselected time intervals via photography. The flow structure of the free convection of water was visualized by mixing tracer particles with the water, and a laser sheet entered from the opposite side of the cooling wall as a light source.

The physical properties of $n$-hexadecane and the experimental condition are listed in Tables 1 and 2, respectively.

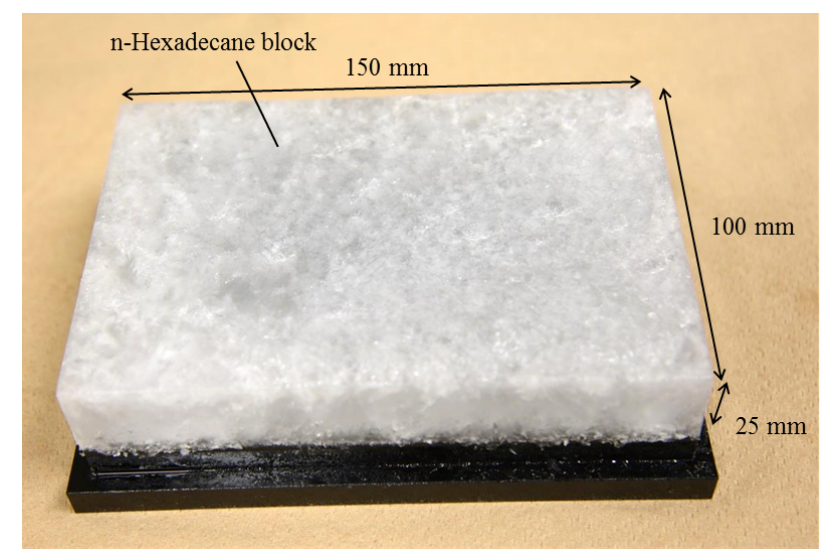

Figure 2. Photo of testing n-hexadecane block

Table 1 Physical properties of n-hexadecane (Seki, 1995, Hardy,1958).

\begin{tabular}{cc}
\hline Parameters, Symbol (Unit) & Values \\
\hline Melting point, $T_{\mathrm{M}}\left({ }^{\circ} \mathrm{C}\right)$ & 18.2 \\
Latent heat of melting, $L\left(\mathrm{~kJ} \mathrm{~kg}^{-1}\right)$ & 229 \\
Density(Solid), $\rho_{\mathrm{S}}\left(\mathrm{kg} \mathrm{m}^{-3}\right)$ & 830 \\
Density(Liquid), $\rho_{\mathrm{L}}\left(\mathrm{kg} \mathrm{m}^{-3}\right)$ & 780 \\
Kinematic viscosity, $v\left(\mathrm{~m}^{2} \mathrm{~s}^{-1}\right)$ & $4.461 \times 10^{-6}\left(\right.$ at $\left.20^{\circ} \mathrm{C}\right)$ \\
\hline
\end{tabular}

Table 2 Experimental condition

\begin{tabular}{cc}
\hline Parameters, Symbol (Unit) & Values \\
\hline Initial temperature of water, $T_{0}\left({ }^{\circ} \mathrm{C}\right)$ & $20.2,23.2,28.2$ \\
Temperature of cooling wall, $T_{\mathrm{w}}\left({ }^{\circ} \mathrm{C}\right)$ & 18.2 \\
Concentration of Surfactant,$c(\mathrm{ppm})$ & 0,1000 \\
\hline
\end{tabular}




\subsection{Data reduction}

The essential quantities measured in the experiment were the ambient water temperature, melting rate, and time elapsed since the start of the data acquisition. The local thermal energy balance at the melting surface of the vertical nhexadecane block can be written as:

$$
\rho_{s} L(d b / d t)_{x, t}=h_{x, t}\left(T_{\infty}-T_{\mathrm{m}}\right)
$$

The local heat transfer coefficient is then defined as follows:

$$
h_{x, t}=\frac{\rho_{s} L(d b / d t)_{x, t}}{T_{\infty}-T_{m}}
$$

\section{Numerical simulation}

The thickness of the melting liquid of n-hexadecane is difficult to measure directly. Therefore, the influence of the melting liquid on heat transfer was evaluated by simulating the thickness of the melting liquid.

\subsection{Numerical model and assumption}

Figure 3 shows the numerical model of the melting n-hexadecane block in water. The melting liquid forms the upward steady flow along the n-hexadecane block and the ambient water forms the downward steady flow adjacent to the melting liquid flow.

This model was developed based on the following assumptions:

(i) Both flows were in laminar regime.

(ii) Boundary-layer approximation was applicable to the fundamental equations of the liquid flow.

(iii) The inertia force and convective heat transfer were ignored in the melting liquid flow.

(iv) All of the inlet heat transferred to the liquid film is consumed by melting.

\subsection{Calculation}

The fundamental equations are applied to the boundary layer approximation. The momentum equation is written as:

$$
\rho_{m} u_{m} \frac{\partial u_{m}}{\partial x}+\rho_{m} w_{m} \frac{\partial u_{m}}{\partial y}=\mu_{m} \frac{\partial^{2} u_{m}}{\partial y^{2}}-g\left(\rho_{m-} \rho_{w}\right)
$$

The energy equation is written as:

$$
\rho_{m} C_{m} u_{m} \frac{\partial T_{m}}{\partial x}+\rho_{m} C_{m} w_{m} \frac{\partial T_{m}}{\partial y}=\lambda_{m} \frac{\partial^{2} T_{m}}{\partial y^{2}}
$$

where $\rho, u, w, \mu, g, c, \lambda$, and $T$ are the density, the velocity of $x$-direction, the velocity of $y$-direction, the viscosity, the gravitational acceleration, the specific heat, the thermal conductivity, and the temperature, respectively. Subscript $m$ indicates the melting liquid and subscript $w$ indicates water. 


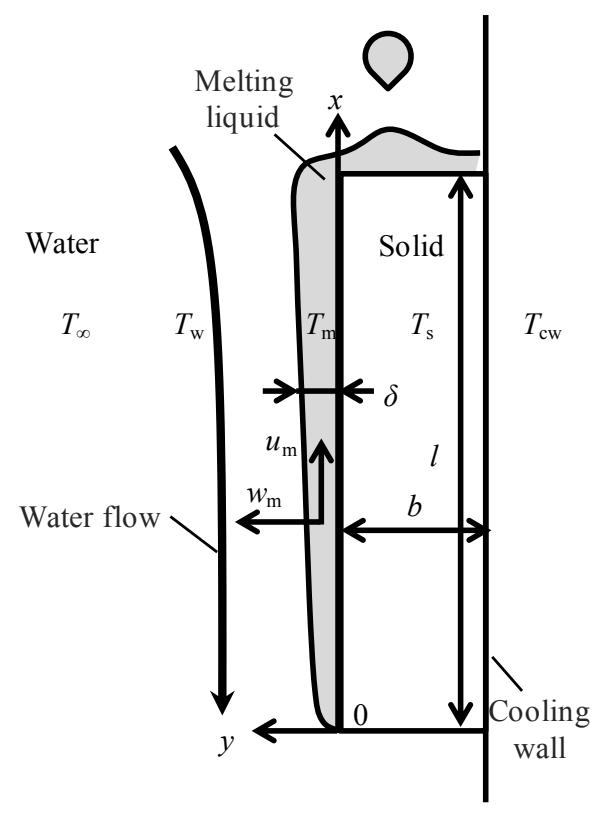

Figure 3. The numerical model of the melting n-hexadecane block.

The boundary condition at $y=0$ is written as:

$u_{m}=0, w_{m}=0, T_{s}=T_{m}=T_{\mathrm{mp}}$

$\lambda_{m} \frac{d T_{m}}{d y}=\left(\frac{1}{h_{m w, x}}+\frac{\delta}{\lambda_{m}}\right)^{-1} \cdot\left(T_{\infty}-T_{s}\right)$

where $T_{\mathrm{mp}}$ is the melting point of the $\mathrm{n}$-hexadecane and $h_{\mathrm{mw}, x}$ is the local heat transfer coefficient between the melting liquid and the ambient water.

The viscosity of n-hexadecane is much larger than the viscosity of the water. Therefore, the boundary condition at the surface of the melting liquid $(y=\delta)$ is given as:

$\mu_{m} \frac{\partial u_{m}}{\partial y}=0$

In this simulation, the inertia force in the melting liquid flow is ignored. Thus, equation (3) is rewritten as:

$u_{m}=\frac{g\left(\rho_{w}-\rho_{m}\right)}{2 \mu_{m}} \cdot y(2 \delta-y)$

The average velocity of melting liquid is given as:

$u_{m, a v e}=\frac{g\left(\rho_{w}-\rho_{m}\right) \delta^{2}}{3 \mu_{m}}$ 
Following the assumption (iii), the heat transfer by convection in the melting liquid flow is ignored. Thus, equation (4) is rewritten as:

$$
T_{m}=\left(\frac{\lambda_{m}}{h_{m w, x}}+\delta\right)^{-1} \cdot\left(T_{\infty}-T_{s}\right) y+T_{s}
$$

Here the energy balance between the amount of heat for the melting of n-hexadecane block and the transferred heat from ambient water to the melting liquid is expressed. The amount of heat $F$ at $x=0$ is described as the following formula:

$$
F=L \rho_{m} u_{m, a v e} \delta=\frac{2 L g \rho_{m}\left(\rho_{w}-\rho_{m}\right) \delta^{3}}{3 \mu_{m}}
$$

Therefore, the differential of amount of heat is expressed as follows:

$$
d F=\frac{2 \operatorname{Lg} \rho_{m}\left(\rho_{w}-\rho_{m}\right)}{3 \mu_{m}} d\left(\delta^{3}\right)
$$

On the other hand, the variation of heat flow by heat conduction from ambient water to the melting liquid at $\mathrm{d} x$ is written as obtained by equation (5) and written as follows:

$$
d F=\lambda_{m} \frac{\partial T_{m}}{\partial y} d x=\left(T_{\infty}-T_{s}\right) \cdot\left(\frac{1}{h_{m w, x}}+\frac{\delta}{\lambda_{m}}\right)^{-1} d x
$$

All of the inlet heat transferred to the liquid film was assumed to be consumed by melting. Thus, the balance equation of the local inlet heat and the local melting heat is given from equations (11) and (12) as:

$$
\frac{2 L g \rho_{m}\left(\rho_{w}-\rho_{m}\right)}{3 \mu_{m}} d\left(\delta^{3}\right)=\lambda_{m} \frac{\partial T_{m}}{\partial y} d x
$$

Then, equation (13) is transformed as follows:

$$
\frac{d \delta}{d x}=\frac{\mu_{m}\left(T_{\infty}-T_{s}\right) \lambda_{m}}{2 L g \rho_{m}\left(\rho_{w}-\rho_{m}\right) \delta^{3}} \cdot\left(\frac{\lambda_{m}}{\delta h_{m w, x}}+1\right)^{-1}
$$

Equation (14) is transformed into a dimensionless equation as follows: 


$$
\frac{d(\delta / l)}{d(x / l)}=\frac{S t e}{2 P r_{m} G r_{m}} \cdot\left(\frac{1}{N u_{m w, x}}+1\right)^{-1} \cdot \frac{1}{(\delta / l)^{3}}
$$

where $G r_{\mathrm{m}}$ is the Grashof number of the melting liquid, $P r_{\mathrm{m}}$ is the Prandtl number of the melting liquid, Ste is the Stefan number of $\mathrm{n}$-hexadecane, and $N u_{\mathrm{mw}, x}$ is the local Nusselt number of the melting liquid and water. These are expressed as:

$$
\begin{aligned}
& G r_{m}=\frac{g \rho_{m}\left(\rho_{w}-\rho_{m}\right) l^{3}}{\mu_{m}^{2}} \\
& P r_{m}=\frac{\mu_{m} C_{m}}{\lambda_{m}} \\
& \text { Ste }=\frac{C_{m}\left(T_{\infty}-T_{s}\right)}{L} \\
& N u_{m w, x}=\frac{\delta h_{m w, x}}{\lambda_{m}}
\end{aligned}
$$

Since the thickness of the melting liquid is quite small in the present condition, the local heat transfer coefficient of the melting liquid and the ambient water are assumed to be equal to the local heat transfer coefficient of the natural convection of the vertical plate. These can be written as:

$$
h_{m w, x}=h_{w, x}=\frac{\lambda_{w} N u_{w, x}}{l-x}
$$

where $\lambda_{\mathrm{w}}$ is the thermal conductivity of water and $N u_{\mathrm{w}, x}$ is the local heat transfer coefficient of the vertical plate. Therefore, equation (15) can be written as follows:

$$
\frac{d(\delta / l)}{d(x / l)}=\frac{S t e}{2 P r_{m} G r_{m}} \cdot\left(\frac{\lambda_{m}}{\lambda_{w}} \cdot \frac{1}{N u_{w, x}} \cdot \frac{1-x / l}{\delta / l}+1\right)^{-1} \cdot \frac{1}{(\delta / l)^{3}}
$$

$N u_{\mathrm{w}, x}$ is defined by the local Grashof number of water $G r_{\mathrm{w}, x}$ and the Prandtl number of water $P r_{\mathrm{w}}$. These are given as follows (Squire, 1938):

$$
\begin{aligned}
& N u_{w, x}=0.508 P r_{w}{ }^{0.5}\left(0.952+P r_{w}\right)^{-0.25} G r_{w, x}{ }^{0.25} \\
& G r_{w, x}=\frac{g \beta_{w}\left(T_{\infty}-T_{s}\right)(l-x)^{3}}{v_{w}^{2}} \\
& P r_{w}=\frac{v_{w}}{a_{w}}
\end{aligned}
$$

where $\beta_{\mathrm{w}}$ is the coefficient of volume expansion of water, $v_{\mathrm{w}}$ is the kinematic viscosity of water, and $a_{\mathrm{w}}$ is the thermal 
diffusivity of water.

The thickness of the melting liquid is obtained by solving equation (21). The equation was solved via the Euler method; the boundary condition at $x=0$ denotes that the initial thickness of the melting liquid was $0.1 \%$ of the initial thickness of the n-hexadecane block.

The local heat transfer coefficient of the n-hexadecane block and ambient water is written as:

$$
h_{x}=\left(\frac{1}{h_{m w, x}}+\frac{\delta}{\lambda_{m}}\right)^{-1}
$$

\section{Results and discussion}

\subsection{Melting liquid}

Figure 4 presents the basic behavior of the melting liquid of n-hexadecane in water. The image (e) was a diagonally forward view at one third upper part of the hexadecane block. Images (a)-(d) are enlarged views of the area within the dotted white line in image (e). The temperature of the water was $23.2{ }^{\circ} \mathrm{C}$. The melting liquid of n-hexadecane did not diffuse in water because it is a water-insoluble material. The melting liquid formed upward flow driven by the density difference of the n-hexadecane and the ambient water. As the n-hexadecane in the liquid phase had a lower density compared to that of water. The melting liquid accumulated at the top of the solid formed droplet shapes, and then levitated vertically (a-d).

Figure 5 shows the calculated thickness of the melting liquid of $n$-hexadecane. The vertical axis $x$ is the distance from the low end of the n-hexadecane block. The horizontal axis $\delta$ is the thickness of the melting liquid. Figure 5 reveals that the thickness of the melting liquid increases drastically near the lower end and increases almost monotonically and at a moderate rate in other parts of the n-hexadecane block. The melting liquid becomes a function of the thermal resistance because its temperature is lower than that of the ambient water. Therefore, melting is enhanced near the lower end owing to the low thermal resistance.

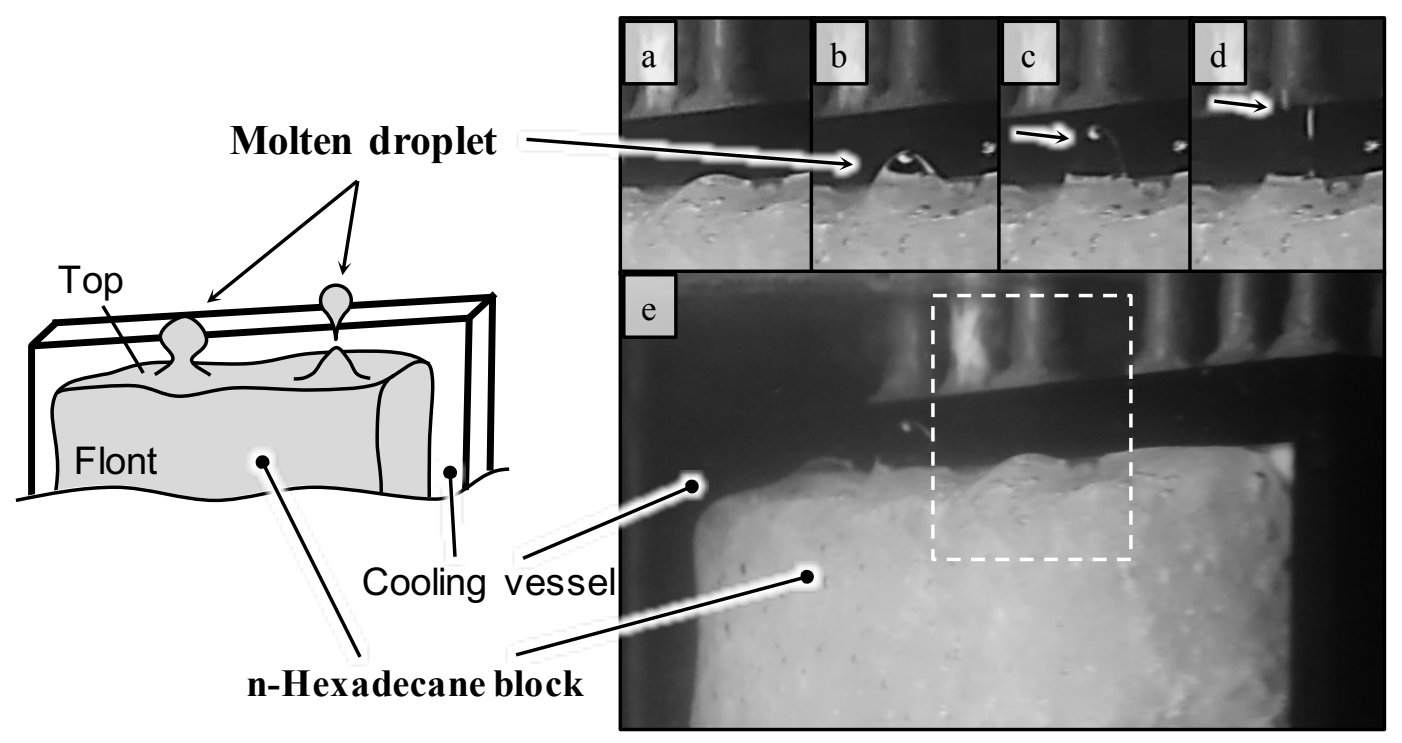

Figure 4. Behavior of melting liquid at $T_{0}=23.2^{\circ} \mathrm{C}$, and $t=5 \mathrm{~min}$ :

(a)-(d) sequence views of the area within the dotted white line in image (e),

(e) upper part of n-hexadecane block 


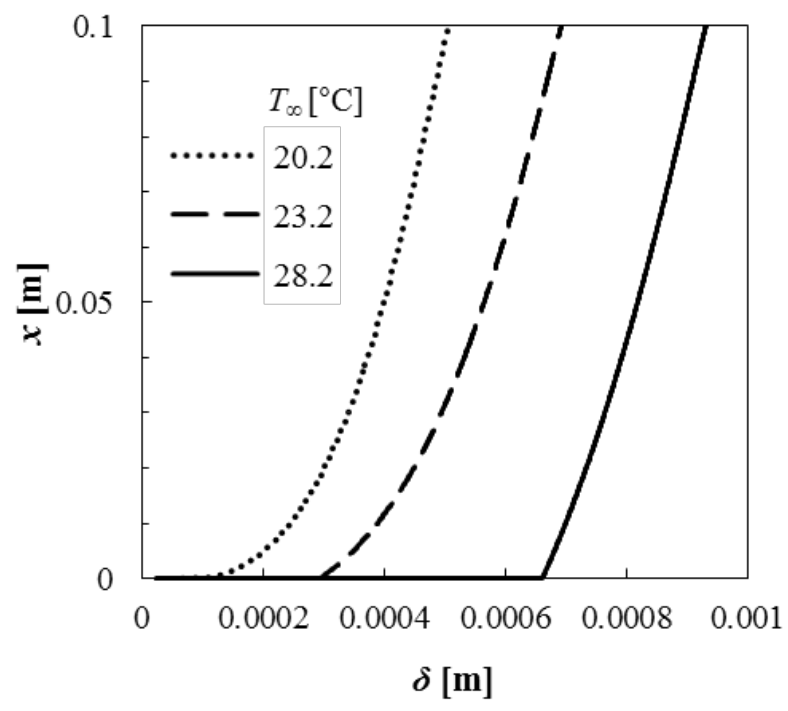

Figure 5. Calculated thickness of the melting liquid of n-hexadecane at $T_{0}=20.2{ }^{\circ} \mathrm{C}, 23.2{ }^{\circ} \mathrm{C}, 28.2{ }^{\circ} \mathrm{C}$

\subsection{Ambient water}

Figure 6 presents the basic behavior of the ambient water visualized by the streak image of the tracer particles. Figure 6 shows that the ambient water approached the top part of the n-hexadecane block, then flowed downward along the block. The downward flow was observed clearly as the temperature difference was large.

Figure 7 presents the velocity field of the ambient water at each point in time, which was obtained with an analysis based on particle image velocimetry. The temperature of water was $28.2{ }^{\circ} \mathrm{C}$. The flows that approached the top part of the $n$-hexadecane block and flows along the block were larger than the other flows. Figure 7 also reveals that velocity decreased as time elapsed, in particular at near the surface of the block.

Figure 8 presents the $x$-direction velocity of the water flow along the $\mathrm{n}$-hexadecane block at $x=80,50$, and $20 \mathrm{~mm}$ from the surface of the n-hexadecane block at $T_{\infty}=28.2{ }^{\circ} \mathrm{C}$ as a function of elapsed time. The $x$-direction velocity was measured within $5 \mathrm{~mm}$ from the solid surface at each $x$-direction position. Figure 8 reveals that velocity decreased by approximately $10 \%$ at $x=20 \mathrm{~mm}$ as time elapsed. This can be attributed to the decrease in the temperature of water near the surface of the block as time elapsed.

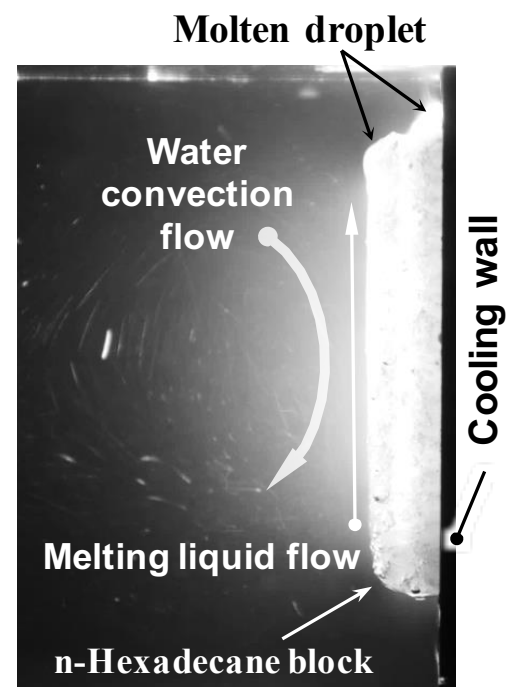

Figure 6. Behavior of ambient water at $T_{0}=28.2^{\circ} \mathrm{C}$, and $t=5 \mathrm{~min}$. 


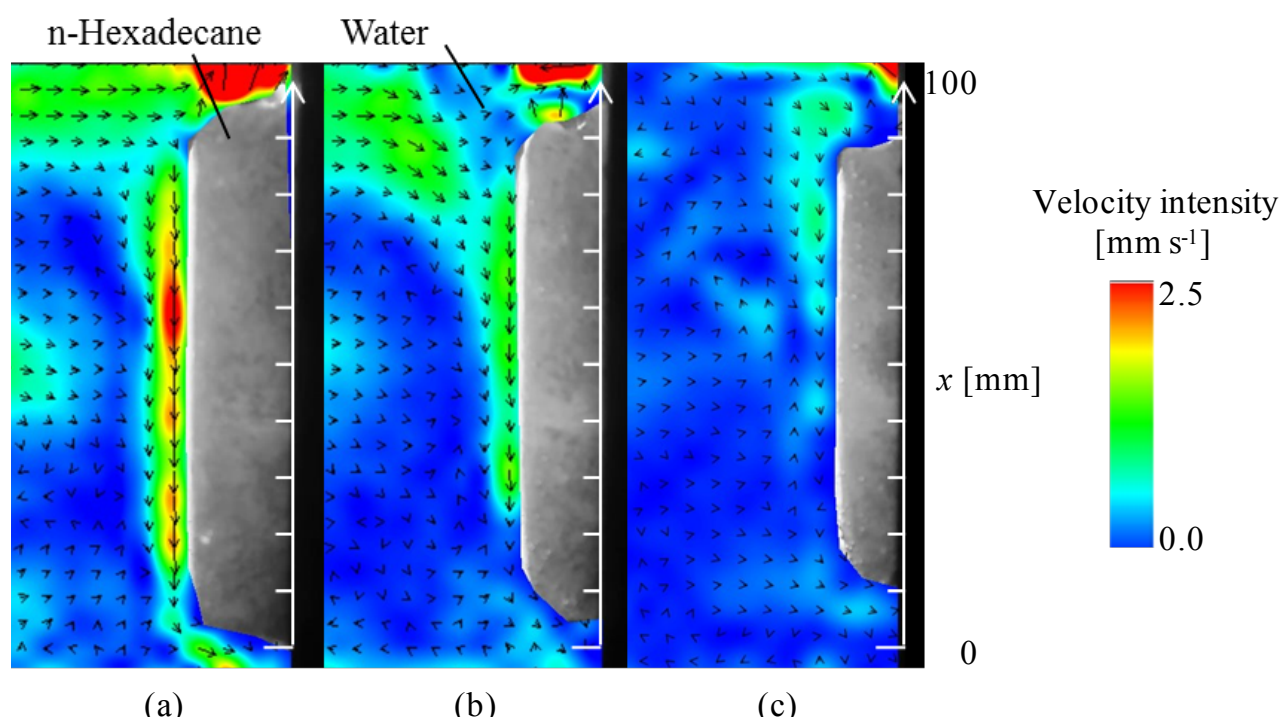

Figure 7. Velocity field of the ambient water at $T_{0}=28.2{ }^{\circ} \mathrm{C}$, and (a) $t=5 \mathrm{~min}$, (b) $t=10 \mathrm{~min}$, (c) $t=15 \mathrm{~min}$.

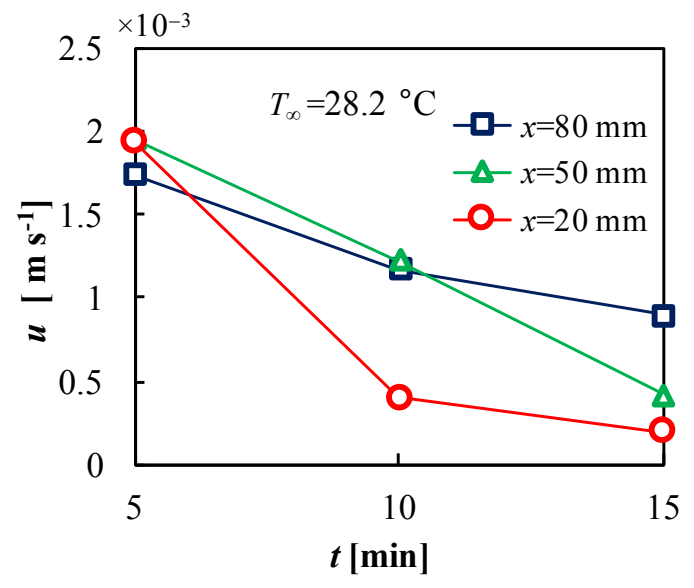

Figure 8. $x$-direction velocity of the water flow along the n-hexadecane block at $T_{\infty}=28.2^{\circ} \mathrm{C}, x=80,50,20 \mathrm{~mm}$

\subsection{Shape variation of melting $n$-hexadecane block}

Figures 9 and 10 present shape variations of the melting of the $n$-hexadecane block with a melting sequence and a melting front at each point in time at water temperatures $T_{0}=20.2{ }^{\circ} \mathrm{C}$ and $28.2{ }^{\circ} \mathrm{C}$. The horizontal axis $b$ is the perpendicular thickness of the $n$-hexadecane block. The vertical axis $x$ is the distance from the bottom of the n-hexadecane block.

Figure 9 reveals that the shape of the n-hexadecane block is rectangular at first. However, the block melts as it receives heat from the ambient water as time elapses. Once the parts of the block at $x=0-15 \mathrm{~mm}$ and $x=85-100 \mathrm{~mm}$ start melting, the upper part melts faster than the lower part of the block.

On the other hand, Figure 10 shows that the lower part of the block melts at higher rate than the upper part at higher water temperatures. This phenomenon may be explained by considering the flow structure of ambient water presented in Figures 6 and 7. At low ambient water temperatures, the water moves along the horizontal direction to reach the upper part of the n-hexadecane block and cools. Cooled water then flows downward along the n-hexadecane block. Consequently, the temperature difference between the water and the $n$-hexadecane block gradually decreases. Therefore, the upper part melted more than the lower part of the n-hexadecane block at $T_{0}=20.2{ }^{\circ} \mathrm{C}$. 

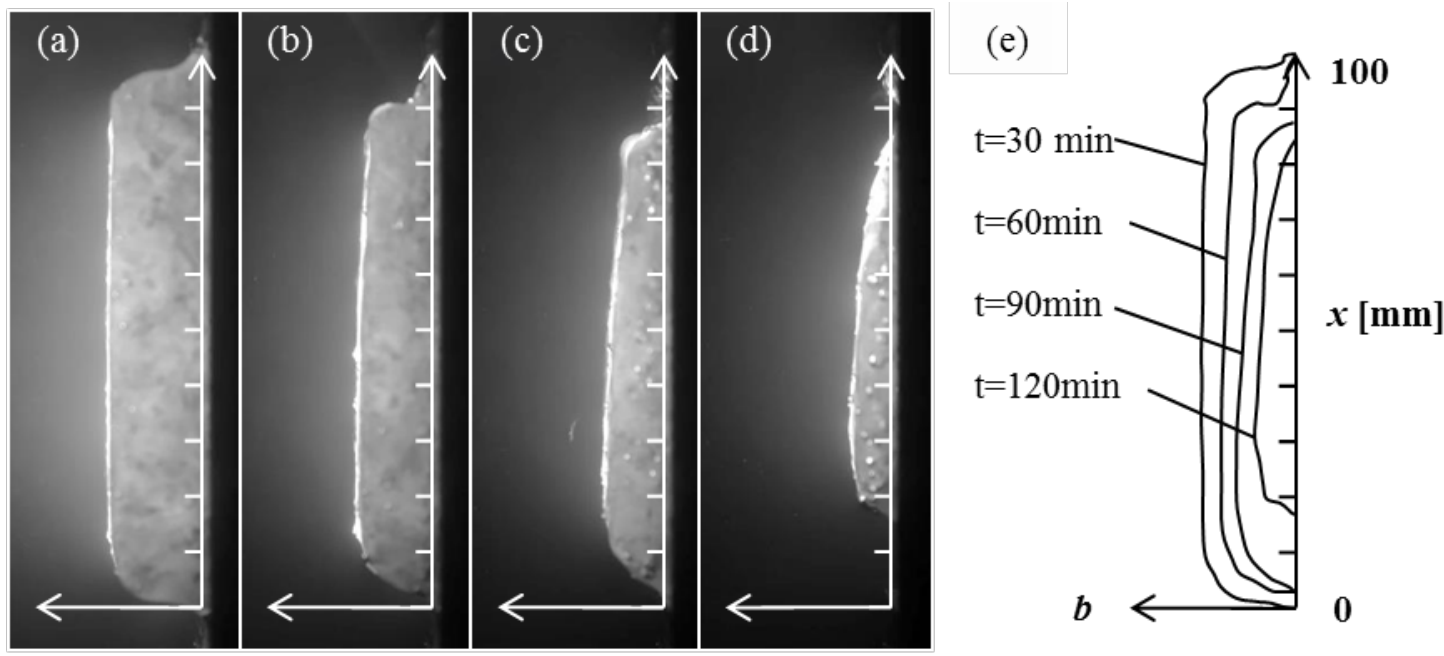

Figure 9. Shape variation of $\mathrm{n}$-hexadecane block at $T_{0}=20.2{ }^{\circ} \mathrm{C}$ :

(a) $t=30$ min., (b) $t=60$ min., (c) $t=90$ min., (d) $t=120 \mathrm{~min}$., (e) melting front at various time instants.
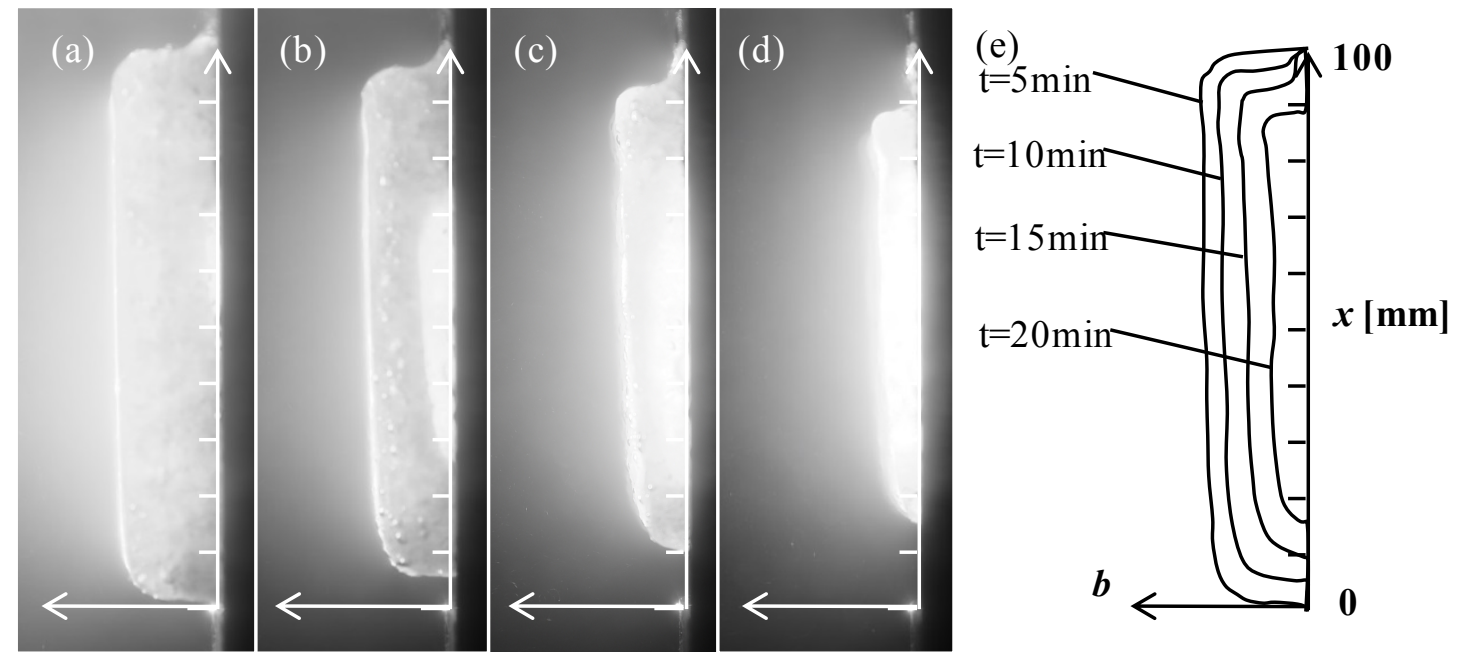

Figure 10. Shape variation of n-hexadecane block at $T_{\infty}=28.2{ }^{\circ} \mathrm{C}$ :

(a) $t=5$ min., (b) $t=10$ min., (c) $t=15$ min., (d) $t=20$ min., (e) melting front at various time instants

The effect of the melting of the upper part was not observed in Figure 10. This may be the result of the efficient upward flow of the melting liquid. The melting liquid flowing upward formed a boundary layer developing along the side of the solid n-hexadecane block on the side of the block. The temperature of the melting liquid is lower than the ambient water temperature. Therefore, increasing the amount of melting liquid markedly prevented melting at the upper part of the block.

\subsection{Variation of local heat transfer coefficient}

Figures 11 (a) and (b) show the calculated and experimental local heat transfer coefficients at each point in time at water temperatures $T_{0}=20.2^{\circ} \mathrm{C}$ and $28.2^{\circ} \mathrm{C}$. The vertical axis is the distance of the lower end of the vertical n-hexadecane block. In Figures 11 (a) and (b), it appears that the calculated local heat transfer coefficients changed slightly, except for those in the top and lower parts of the block. This is explained by the local heat transfer coefficient between the melting liquid and ambient water $h_{\mathrm{mw}, x}$ and the calculated thickness of the melting liquid $\delta$. That is, the local heat transfer coefficient between the melting liquid and ambient water $h_{\mathrm{mw}, x}$ increased with an increase in $x$ as shown in equation (20). On the other hand, the calculated thickness of the melting liquid $\delta$ decreased as the water flowed downward along the n- 
hexadecane block as described in section 5.1. Consequently, the calculated local heat transfer coefficients almost did not change.

Figure 11 (b) reveals that the local heat transfer coefficients increased in most locations as time elapsed in the experiment. This may result from the fact that the velocity of the ambient water flow along the n-hexadecane block decreased as time elapsed. That is, the decreasing velocity of the water flow decreased the flow resistance of the melting liquid of the $n$-hexadecane along the block. Therefore, the velocity of the melting liquid increased and its thickness decreased. Consequently, the thermal resistance of the melting liquid decreased, and the local heat transfer coefficient increased as time elapsed.

However, it was found that the unexpected difference between the experimental result and the analytical one was shown for the high temperature condition. The analysis was a steady-state calculation in the case where the flow of the molten liquid film can be simulated in a modeled form. In fact, the analytical model constructed in this research cannot be applied when melting progresses and the surface shape changes, or when the melting becomes fast and the unsteadystate behavior becomes strong. On the other hand, it was observed that the melting liquid developed with non-film shape under high temperature condition. This flow induced the reducing the thickness of the melting liquid film. As a result, the heat transfer coefficient increased by elapse of time in the experiment due to decline the thermal resistance. Therefore, an advanced model including an unsteady-state melting behavior should be suggested for high temperature conditions.

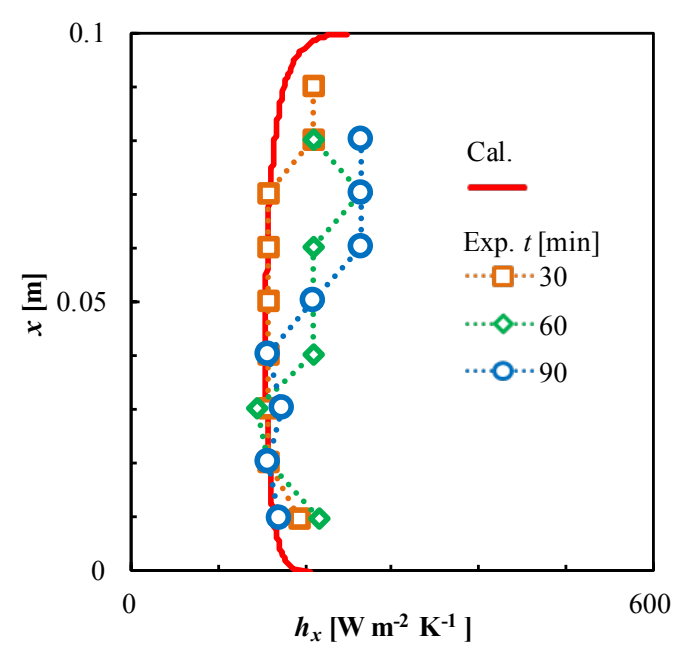

(a)

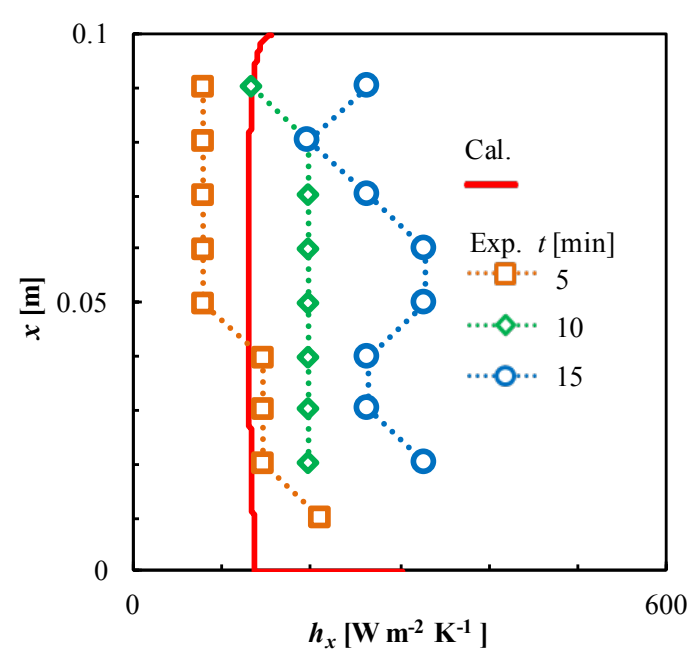

(b)

Figure 11. Calculated and experimental local heat transfer coefficient at each time instant at water temperatures (a) $T_{0}=20.2{ }^{\circ} \mathrm{C}$ and (b) $T_{0}=28.2{ }^{\circ} \mathrm{C}$.

\section{Conclusions}

Experimental and numerical studies were carried out to determine both the melting behavior and heat transfer characteristics of a vertical n-hexadecane block immersed in water. As the conclusions from experimental results, it flows upward along the n-hexadecane block, accumulates at the top of the solid as a droplet, and then flows upward vertically because the melting liquid of n-hexadecane does not diffuse in water. The thickness of the melting liquid of n-hexadecane, determined by calculation, increased drastically near the lower end, and increased almost monotonically and at a mild rate in other parts of the block. In addition, the ambient water approached the top part of the n-hexadecane block and flowed downward along the block. The velocity of the downward flow decreased as time elapsed. On the other hand, the ambient water flow along the vertical n-hexadecane block enhanced the melting heat transfer at the upper part of the block. This effect became clearer with decreasing ambient water temperature. The upward flow of the melting liquid prevented heat transfer owing to melting at the upper part of the block. This effect became clearer with increasing ambient water temperature.

The analytical local heat transfer coefficient showed good agreement with the experimental value as water 
temperature decreased. The calculated local heat transfer coefficients changed slightly except for those at the top and low parts of the block. The local heat transfer coefficients increased in most locations as time elapsed in the experiment. However, the tendency that the unexpected difference between the experimental result and the analytical one was found for the high temperature condition. The reason why the fact was that the present analytical model could not express the significant shape change and the unsteady-state behavior. Therefore, when the melting behavior exhibits an extreme unsteady process, a more advanced analytical model should be developed.

\section{References}

Bosholm F., López-Navarro A., Gamarra M., Corberán J M., Payá J., Reproducibility of solidification and melting processes in a latent heat thermal storage tank, Int. J. Refrigeration, Vol. 62 (2016), pp. 85-96.

Hardy R C., Viscosity of n-Hexadecane, Journal of Research of the National Bureau of Standards, Vol.61, No.5 (1958), pp.433-436.

Horibe A., Jang H., Haruki N., Kanbara H., Takahashi K., Melting and solidification heat transfer characteristics of phase change material in a latent heat storage vessel: Effect of perforated partition plate, Int. J. Heat Mass Trans., Vol. 82 (2015), pp. 259-266.

Nomura T., Okinaka N., Akiyama T., Technology of latent heat storage for high temperature application: a review, ISIJ International, Vol. 50, No. 9 (2010), pp. 1229-1239.

Saito A., Imamura T., Utaka Y., Saito A., On the contact heat transfer with melting (Direct contact melting process within an inclined rectangular cross-section), JSME Int. J., Vol. 32, No. 3 (1989), pp. 411-419.

Seki N., Chikunetsu kogaku, Morikita Publishing Co., Ltd. Tokyo, Vol.1 (1995). (in Japanese)

Squire H B., Goldstein S. (Ed.), Modern developments in fluid dynamics, Oxford London, Vol.2 (1938).

Veerakumar C., Sreekumar A., Phase change material based cold thermal energy storage: Materials, techniques and applications - A review, Int. J. Refrigeration, Vol. 67 (2016), pp. 271-289.

Yamada M., Fukusako S., Kawanami T., Performance analysis on the liquid-ice thermal storage system for optimum operation, Heat mass transfer, Int. J. Refrigeration, Vol.25, Issue 2 (2002), pp. 267-277.

Yamada M., Fukusako S., Sayed M EB., Experiments on melting of a vertical ice layer immersed in immiscible liquid, Heat mass transfer, Vol.32 (1997), pp. 447-454. 